\title{
Characterization, Optical and Conductivity Study of Nickel Oxide based nanocomposites of Polystyrene
}

Shimaa Saeed El-Khiyami ( $\nabla$ shelkhyami@sci.cu.edu.eg )

Cairo University https://orcid.org/0000-0001-6730-7574

A.M. Ismail

National Research Centre

R.S. Hafez

Cairo University

\section{Research Article}

Keywords: Polystyrene, Nickel oxide NP, Optical properties, electrical conductivity, FT-IR, X-ray

Posted Date: April 22nd, 2021

DOl: https://doi.org/10.21203/rs.3.rs-439816/v1

License: (1) This work is licensed under a Creative Commons Attribution 4.0 International License.

Read Full License 


\title{
Characterization, Optical and Conductivity Study of Nickel Oxide based nanocomposites of Polystyrene
}

\author{
S. S. El-Khiyami ${ }^{1 *}$, A.M. Ismail ${ }^{2}$, R.S. Hafez ${ }^{1}$ \\ ${ }^{1}$ Physics Department, Faculty of Science, Cairo University, Cairo, 12613 Egypt. \\ ${ }^{2}$ Spectroscopy Department, Physics Division, National Research Centre, Giza, 12622 Egypt.
}

\begin{abstract}
Different concentrations of nickel oxide ( $\mathrm{NiO})$ nanoparticles were successfully inserted into polystyrene (PS) polymer matrix using the solution casting method. X-ray diffraction (XRD), Fourier transform infrared (FT-IR), high-resolution scanning electron microscope (SEM), and UV-Vis techniques are used to characterize the nanocomposites. XRD, SEM, and FT-IR results indicate that PS and NiO nanoparticles have a good interaction and a high degree of complexity. Using UV-Vis technique, the absorbance of nanocomposites is improved by increasing the nanofiller content. Both the Urbach energy (EU) and the optical energy gap (Eg) were calculated using the Urbach relation and the Tauc model. Refractive indices values of nanocomposites display raising trend with $\mathrm{NiO}$ content which promote $\mathrm{PS} / \mathrm{NiO}$ nanocomposites for use in photonic applications and designing optical devices. Nanocomposites' electrical conductivity was also investigated. The electrical conductivity of the nanocomposites has increased significantly due to the uniform dispersion of $\mathrm{NiO}$ nanoparticles and by increasing its content. Conduction is achieved by correlated barrier hopping $(\mathrm{CBH})$.
\end{abstract}

Keywords: Polystyrene, Nickel oxide NP, Optical properties, electrical conductivity, FT-IR, X-ray.

\section{Introduction}

A polymer nanocomposite ( $\mathrm{NCs}$ ) is a composite material consisting of a polymer matrix and at least one nanometric dimension inorganic material. As a result of their applications in electronic and photonic devices, rechargeable batteries, and supercapacitors, the resulting hybrid materials are promising [1-9]. Inorganic nanoparticles are applied to polymeric materials to strengthen their physical properties. Polymer/inorganic NCs combine the properties of the two components. This means that polymers with strong optical properties, durability, and hardness will help inorganic materials become less brittle. Inorganic materials also increase polymer strength [10]. Polystyrene (PS) is a thermoplastic polymer with excellent optical clarity and chemical tolerance to diluted acids and bases due to its lack of crystallinity. Polystyrene has a wide range of uses due to its low cost and ease of manufacturing, including disposable consumer plastic products and parts for optical, electronic/electrical, and medical applications.

*Corresponding author “E-mail: shelkhyami@sci.cu.edu.eg (S. S. El-Khiyami)” 
Similarly, nickel (II) oxide (NiO) has gained a lot of attention in recent years as a promising inorganic material for a range of applications, including gas sensors, batteries, electrodes, and electronics [11-16]. Various research groups have documented structural, thermal, magnetic, and other physical properties of $\mathrm{PS} / \mathrm{NiO}$, Hybrid silica/PS, PS/SiO $2, \mathrm{PS} / \mathrm{Fe}_{3} \mathrm{O}_{4}, \mathrm{PS} / \mathrm{HgS}$, and $\mathrm{CaCO}_{3} / \mathrm{PS}$ [17-22]. Nickel oxide nanoparticles (NiO) NP were inserted into a polystyrene matrix in this work. $\mathrm{PS} / \mathrm{NiO} \mathrm{NCs}$ is compared to pure PS in terms of structural, optical, and conductivity investigation.

\section{Experimental Part.}

\subsection{Chemicals.}

All the chemicals used in this study were not purified further. Polystyrene (PS) [average $\mathrm{Mw}_{\mathrm{w}}=$ 350,000] and nickel (II) oxide (NiO) nano powder were purchased from Sigma-Aldrich co. The solvent used in this study is tetrahydrofurane, was purchased from Fisher scientific for chemicals, UK.

\subsection{Synthesis of PS/NiO nanocomposites.}

The synthesis procedures used for preparation of $\mathrm{PS} / \mathrm{NiO}$ nanocomposite films using solution casting method are shown in Fig. 1. A appropriate amount of polystyrene (PS) and nickel oxide nanoparticles (NiO) NPs was dissolved in $50 \mathrm{ml}$ of tetrahydrofurane separately, The mixture was then vigorously stirred for 3 hours at $40^{\circ} \mathrm{C}$. NiO NPs solution with mass fractions 2, 4, 6, 8 and $10 \mathrm{wt} \%$ was applied to the polymer solution, for about 30 minutes, the viscous liquids were sonicated. When dispersing nanoparticles in a polymer matrix, two essential goals must be met, firstly: to break them down into their smallest components, and secondly: to make them homogeneous in a polymer matrix. As a result, the ultrasonication method is used to achieve these objectives and exploit the unique properties of NiO NPs. The nanocomposite solutions were slowly poured into washed glass Petri dishes and held at $40{ }^{\circ} \mathrm{C}$ in a vacuum oven. until the solvent completely evaporated. Pure PS film has also been prepared for comparison under the same conditions. In vacuum desiccator the final films were stored.

\subsection{Measurements.}

X-ray diffraction (XRD) analysis was conducted on X'Pert-PRO-PANalytical channel control using $\mathrm{Cu}-\mathrm{K} \alpha$ target $\left(\lambda=1.5406 \AA\right.$, scans were collected over a $2 \theta$ range of $\left.5^{\circ}-60^{\circ}\right)$. Scherrer's formula was used to measure the average crystallite size of $\mathrm{NiO}$ nanoparticles based on line broadening. Fourier transform infrared (FT-IR) measurements were recorded using JASCO, FT/IR-6100. FT-IR measurements were taken in the spectral range of 4000-400 $\mathrm{cm}^{-1}$. High-resolution scanning electron microscope (HRSEM) was performed using SEM Model Quanta 250 FEG. The optical measurements of the prepared films were investigated using UV-630 (Shimadzu) UV-VIS-NIR 
spectrophotometer. Dielectric measurements were performed using Broadband Dielectric Spectroscopy (BDS) type Novocontrol concept 40.

\section{Results and discussion.}

\subsection{X-ray diffraction analysis}

The XRD of NiO NPs, PS, and PS doped with various NiO NP concentrations is investigated. Fig. 2 shows XRD pattern of $\mathrm{NiO} N P s$, it has characteristic diffraction peaks at $2 \theta=37.2^{\circ}, 43.2^{\circ} .62 .8^{\circ}$, $75.4^{\circ}$ and $79.4^{\circ}$ which corresponded to (111), (200), (220), (311) and (222) lattice planes respectively, that related to face-centered cubic crystal structure [23, 24]. The position of the peak and the relative strength of the characteristic peaks are accorded with standard spectrum (JCPDS, No. 04-0835). NiO NPs have a single phase XRD pattern, and there are no other impurities peaks. The mean crystallite size of NiO NPs was calculated from the line broadening of the diffraction peaks using Scherrer's formula [25]

$$
D=\frac{0.9 \lambda}{\beta \cos \theta}
$$

where $\mathrm{D}$ is the crystallite size, $\lambda=0.154 \mathrm{~nm}$ is the $\mathrm{X}$-ray wavelength, $\beta$ is the full width at half maximum (FWHM) of the diffraction peak (in radian) and $\theta$ is the Bragg's diffraction angle (in degree) of the peak maximum. The average crystallite size of NiO NPs was found to be nearly 18 nm. XRD scans of PS homopolymer and PS filled with different ratios of $\mathrm{NiO}$ nanoparticles are illustrated in Fig. 3. XRD pattern of PS shows a broad hump at $2 \theta=20.3^{\circ}$ that indicate the amorphous structure of PS [26]. Figs. 3b-3f show XRD patterns of PS/ NiO NCs, it can be seen that with increasing $\mathrm{NiO} \mathrm{NPs}$ the characteristic hump of PS is shifted to $2 \theta=19.7^{\circ}$. Also, the peak broadening increased with increasing NiO NPs. The characteristic diffraction peaks of NiO NPs at $2 \theta$ $=75.4^{\circ}$ and $79.4^{\circ}$ disappeared. As well the peak position of NiO NPs at $2 \theta=62.8^{\circ}$ was shifted to $2 \theta=$ $63.2^{\circ}$. Diffraction peaks at $2 \theta=37.2^{\circ}, 43.2^{\circ}$ and $63.2^{\circ}$ are increasing with an increase in the concentration of NiO NPs. Furthermore, these results suggest that the NiO NPs increased the nanocomposite system's disorder, and that the nanocomposite components obtained are compatible, confirming their complexity (see scheme 1).

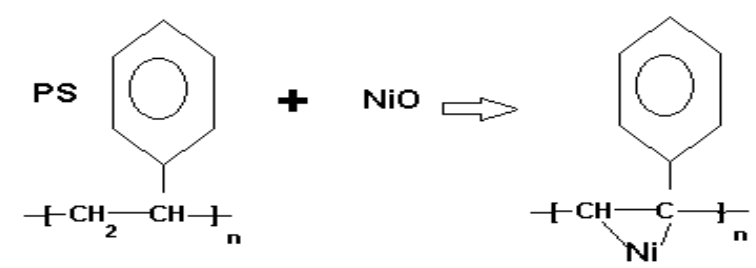

Scheme 1: Possible interaction between PS and NiO NPs. 


\subsection{Fourier transform infrared analysis}

FT-IR absorption spectra for the PS and PS/NiO NCs were performed at room temperature within a range 4000-400 $\mathrm{cm}^{-1}$ as shown in Fig. 4. FT-IR spectrum of PS (Fig. 4a) shows absorption band at $3025 \mathrm{~cm}^{-1}$ which attributed to axial deformation of aromatic $\mathrm{C}-\mathrm{H}$. The asymmetric and symmetric stretching vibrations of $\mathrm{CH}$ and $\mathrm{CH}_{2}$ groups are seen at 2920 and $2844 \mathrm{~cm}^{-1}$, respectively. The bands at 1600 and $1492 \mathrm{~cm}^{-1}$ are related to the stretching vibration of $\mathrm{C}=\mathrm{C}$ in aromatic ring. The angular deformation of $\mathrm{CH}_{2}$ symmetric and asymmetric is shown at $1451 \mathrm{~cm}^{-1}$. The stretching bands at 1067 and $1027 \mathrm{~cm}^{-1}$ are related to $\mathrm{C}-\mathrm{C}$ stretching vibration. The out-of-plane deformation of $\mathrm{C}-\mathrm{H}$ aromatic is seen at $748 \mathrm{~cm}^{-1}, 695 \mathrm{~cm}^{-1}$ and $537 \mathrm{~cm}^{-1}$ [27-29]. There is a new band appeared at $427 \mathrm{~cm}^{-1}$ after doping PS with NiO NPs (Figs. 4b-4f) which attributed to Ni-O [30]. The strength of absorption bands in nanocomposite samples containing $>2 \mathrm{wt} \% \mathrm{NiO}$ NPs decreased as the NiO NPs content increased. The presence of PS and $\mathrm{NiO}$ nanoparticles in the prepared nanocomposites was revealed by FT-IR, suggesting successful complexation between them.

\subsection{High-resolution scanning electron microscope analysis (SEM)}

The morphology of pure PS and PS/NiO NCs as determined by SEM is depicted in Fig.5 (a-f). As seen in Fig. 5a, which represents pure PS with $X 3000$ magnification micrograph, the surface is homogeneous and smooth. Fig. 5(b-f) shows the distribution of $\mathrm{NiO}$ nanoparticles inside the PS matrix with $\times 800$ magnification. $\mathrm{NiO}$ nanoparticles appeared as tiny white particles, which dispersed uniformly on the polymer matrix surface. As nanofiller content in the nanocomposites increases, the inertia for these nanofillers to form agglomerations is also increasing and nanoclusters are forming. The attractive van der Waals force causes nanoparticles to clump together between neighboring particles. The size of the nanoclusters depends on the amount and size of nanoparticles inside the polymer matrix.

\subsection{UV-Vis analysis}

Fig. 6 illustrates the variation of absorbance of pure PS and PS/NiO NCs as a function of wavelength at room temperature. The figure shows that all nanocomposites spectra have high absorbance values near the fundamental absorption edge. (250 -315 nm), then the absorbance decreases with increasing of wavelength. There is an absorption band around the wavelength of $260 \mathrm{~nm}$ for pure PS [31]. In the case of PS doped with $\mathrm{NiO}$ nanoparticles, a new shoulder like peak appeared at about $286 \mathrm{~nm}$. The absorbance of nanocomposites is increased by increasing percentages of nanofiller weight relative to pure PS. This phenomenon indicates that $\mathrm{NiO}$ nanoparticles were successfully integrated and 
interacted with the polymer matrix [32]. Furthermore, no peak was observed in the visible region of the absorption spectra of nanocomposites. This finding indicates that synthesized nanocomposite can be used as UV-filter and UV-shielding block [33].

\subsection{Optical constants}

\subsubsection{Optical absorption edge and Urbach energy}

Using the following equation, the optical absorption coefficient $(\alpha)$ was determined from absorbance. [34]

$$
\alpha(\lambda)=2.303 \frac{A}{d}
$$

Where $\mathrm{d}$ is the thickness of the film and $\mathrm{A}$ is the absorbance. Fig. 7 illustrates the dependence of optical absorption coefficient $(\alpha)$ on the photon energy (hu) for PS and PS/NiO NCs. The absorption edge values of PS and PS/NiO NCs are obtained from Fig.6 by extrapolation of the linear relationship to zero absorption. Table 1 represents the obtained values. The absorption edge values for the analyzed samples decrease as the nanofiller content increases due to changes in PS crystallinity. The absorption coefficient obeys Urbach empirical relation [35]

$$
\alpha(v)=\alpha_{0} \exp \left(\frac{\boldsymbol{h} v}{E_{U}}\right)
$$

Where $\alpha_{0}$ is a constant and $\mathrm{E}_{\mathrm{U}}$ (Urbach energy) is the width of the tail of the localized states within the band gap. Urbach energy values of PS/NiO NCs were determined by taking reciprocal of slopes of the linear parts of the graphs shown in Fig. 8. As the nanofiller ratio in the polymer matrix increases, the Urbach energy values [see Table 1] increase, suggesting an increase in the number of charge trapping centers.

\subsubsection{Optical energy gap}

The absorption coefficient helps to determine the nature of electron transition. In general, direct and indirect transitions can occur at the absorption edge of materials. The absorption coefficient $(\alpha)$ is related to the optical band gap $\left(\mathrm{E}_{\mathrm{g}}\right)$ by Tauc relation $[36]$

$$
\alpha h v=\beta\left(h v-E_{g}\right)^{m}
$$

where $\beta$ is constant and $\mathrm{m}$ is the index with the value determined by the type of possible electronic transitions. $m=2$ or $1 / 2$ for indirect and direct allowed transitions respectively. In order to obtain the values of $E_{g}$ for studied samples, we plot relation between $(\alpha h v)^{2}$ and $(\alpha h v)^{1 / 2}$ as a function of photon energy as shown in Fig. 9. Direct and indirect optical band gaps for pure PS and PS/NiO NCs were determined from extrapolations of the liner portions of $(\alpha h v)^{2}$ and $(\alpha h v)^{1 / 2}$ to zero absorption on hv 
axis. The direct and indirect optical band gap values of PS decreased as the ratio of $\mathrm{NiO}$ nanoparticles increased, according to the findings. [see Table 1], this behavior may be caused by the creation of the localized states within the polymer matrix.

\subsubsection{Refractive index}

Based on the following relation $[37,38]$, the Refractive indices (n) of pure PS and PS/NiO NCs were determined

$$
\frac{n^{2}-1}{n^{2}+2}=1-\sqrt{\frac{E_{g(\text { indirect })}}{20}}
$$

Fig. 10 shows the relation between refractive index of nanocomposites and the ratio of $\mathrm{NiO}$ nanoparticles. Refractive indices display raising trend with $\mathrm{NiO}$ content. The packing density and number of charge carriers in the samples under review increased as the $\mathrm{NiO}$ ratio increased, refractive indices are therefore increasing. The obtained values of the refractive indices indicate that $\mathrm{PS} / \mathrm{NiO}$ NCs can be used for photonic applications and designing optical devices.

\subsection{Conductivity measurements}

In many cases, conductivity may be due to hopping, depending on different parameters, for example temperature, frequency and filler concentration.

\subsubsection{Temperature dependence conductivity}

The variation of conductivity In $\left(\sigma_{\mathrm{ac}}\right)$ of pure PS and PS/NiO nanocomposite samples with inverse temperature at frequency of $1 \mathrm{kHz}$ is shown in Fig. 11. The plot behavior shows that the conductivity of the studied samples is thermally activated following Arrhenius law:

$$
\sigma(\mathrm{T})=\mathrm{A}_{0} \exp (-\Delta \mathrm{E} / \mathrm{kT})
$$

where $\mathrm{A}_{0}$ is the pre-exponential factor, $\Delta \mathrm{E}$ is the activation energy, $\mathrm{T}$ and $\mathrm{k}$ are temperature and Boltzmann constant respectively. As shown in Fig. 11, there are two different regions: I (403-343 K) and II (343-293 K). Region II has very low activation energy values and the conductivity is almost temperature independent. Table 2 shows the values of activation energy for PS/NiO nanocomposite films in region $\mathrm{I}$, values ranging from $0.65 \mathrm{eV}$ for pure $\mathrm{PS}$ to $0.15 \mathrm{eV}$ for $\mathrm{PS} / 8 \mathrm{wt} \% \mathrm{NiO}$ nanocomposite. These values can be associated with ion hopping among vacant sites [39]. The activation energy reduced by increasing the percentage of $\mathrm{NiO}$ nanoparticles and then starting to increase at the percentage of $10 \mathrm{wt} \%$. This could be due to the difference in dispersion of $\mathrm{NiO}$ nanoparticles in PS sample. The formation of aggregates or clusters in the polymeric matrix resists the hopping of electron from one particle to another particle leading increase in the activation energy. In general, the conductivity increases by increasing the temperature and the percentage of $\mathrm{NiO}$ 
nanoparticles which improving the conduction of the nanocomposites. The elongation of polymer chain length and polaron hopping are responsible for the increase in conductivity. It was also discovered that pure $\mathrm{NiO}$ has a larger surface area than pure Polystyrene. As a result, these composites are promising materials for use in transformers, energy storage systems, and rechargeable batteries as a soft electromagnetic material.

\subsubsection{Frequency dependence conductivity}

The fitted data of AC conductivity for pure PS and PS/NiO nanocomposites as a function of frequency at selected temperatures $20^{\circ} \mathrm{C}, 50^{\circ} \mathrm{C}, 70^{\circ} \mathrm{C}$ and $100^{\circ} \mathrm{C}$ are shown in Fig. 12. The dots are experimental data points and the lines are the fitting. The figure shows that the electrical conductivity of nanocomposites is increasing with frequency. The increase in electrical conductivity with frequency is due to the polarization of the space charge that occurs at low frequencies, as well as to the hopping of charge carriers. The frequency dependent conductivity is generally represented by the universal dispersion relaxation (UDR) or Jonscher's power law given by [40]

$$
\sigma_{\mathrm{ac}}(\omega)=\sigma_{\mathrm{dc}}+\mathrm{A}(\mathrm{T}) \omega^{\mathrm{S}}
$$

where $\sigma_{\mathrm{dc}}$ is the dc conductivity of the sample, $\omega$ is the angular frequency, $\mathrm{A}$ is a temperature dependent constant and $\mathrm{s}$ is the power law exponent. The exponent s represents the degree of interaction between mobile ions and the environments surrounding them. Many manifestations of the hopping models and experiments gave value of $s$ in the range of $0<s<1$. The thermally activated hopping process between two sites separated by an energy barrier explains the transport mechanism of mobile ions. [41, 42]. When trying to fit the obtained data to the above single power term expression, the data did not give a good fit except for PS/10wt\% NiO composite sample. However, an excellent fit was obtained using the two terms power law [see Fig. 12(a-d)], known as the superlinear power law (SLPL) given by the following equation [43-45]

$$
\sigma_{\mathrm{ac}}(\omega)=\sigma_{\mathrm{dc}}+\mathrm{A}_{1} \omega^{\mathrm{s1}}+\mathrm{A}_{2} \omega^{\mathrm{s} 2}
$$

The fitting parameters $s_{1}, s_{2}, \ln A_{1}$ and $\ln A_{2}$ and $\ln \left(\sigma_{d c}\right)$ at room temperature are shown in Table 3. Fig.13 and Fig.14 represent the fitted data at different temperatures for the studied nanocomposites. With increasing temperature, the general pattern of decreasing s1 and s2 could be attributed to correlated barrier hopping [46, 47]. 


\subsection{Conclusion}

$\mathrm{PS} / \mathrm{NiO}$ nanocomposite films prepared by using solution casting method. The prepared samples were subjected to study characterization, optical and electrical conductivity. The formation of the nanocomposite films has been identified using XRD and FTIR techniques. By increasing the addition of $\mathrm{NiO}$ NP the disorder of the nanocomposite system of PS increase, Urbach energy values of PS/NiO NCs increases due to increasing in number of charge trapping centers, the direct and indirect optical band gap values decreases due to the creation of the localized states within the polymer matrix. Refractive indices values display raising trend with increasing $\mathrm{NiO}$ content because the increasing in the packing density and the number of charge carriers in the samples, so PS/NiO nanocomposites suitable for photonic applications and designing optical devices. The electrical conductivity increased with increasing the percentage of $\mathrm{NiO} \mathrm{NP}$. The most common mechanism is correlated barrier hopping $(\mathrm{CBH})$ which can contribute to the ac conduction behavior in the present system.

\section{References}

[1] G. N. Smith, J. E. Hallett, P. Joesph, S. T. McNally, T. Zhang, F. D. Blum, J. Eastoe, Structural studies of thermally stable, combustion-resistant polymer composites, Polym. J. 49, 711 (2017).

[2] M. H. Naveen, N. G. Gurudatt, Y. B. Shim, Applications of conducting polymer composites to electrochemical sensors: A review, Appl. Mater. 9, 419 (2017).

[3] C. M. Wang, C.Y. Chen, W. S. Liao, Paper-Polymer Composite Devices with Minimal Fluorescence Background, Chim. Acta. 963, 93 (2017).

[4] L. Wang, Y. Liu, Z. Zhang, B. Wang, J. Qiu, D. Hui, S. Wang, Polymer composites-based thermoelectric materials and devices, Compos. B 122, 145 (2017).

[5] C. Zhang, T. F. Garrison, S. A. Madbouly, M. R. Kessler, Recent advances in vegetable oil-based polymers and their composites, Prog. Polym. Sci. 71, 91 (2017).

[6] S. Devikala, P. Kamaraj, M. Arthanareeswari, AC conductivity studies of PMMA/TiO 2 composites, Mater. Today 5, 8678 (2018).

[7] T. Wang, G. Chen, C. Wu, D. Wu, Study on the graphite nanosheets/resin shielding coatings, Prog. Org. Coat. 59, 101 (2007).

[8] S.V. Kuppua, A. R. Jeyaramanb, P. K. Guruviaha, S. Thambusamya, Preparation and characterizations of PMMA-PVDF based polymer composite electrolyte materials for dye sensitized solar cell, Curr. Appl. Phys. 18, 619 (2018). 
[9] C. H. Sengottaiyan, R. Jayavel, P. Bairi, R.G. Shrestha, K. Ariga. L. K. shrestha, Cobalt Oxide/Reduced Graphene Oxide Composite with Enhanced Electrochemical Supercapacitance Performance, Bull. Chem. Soc. 90, 955 (2017).

[10] A.R.Mahdavian, M.Ashjari, A.B.Makoo, Preparation of poly(styrene-methyl methacrylate)/SiO 2 composite nanoparticles via emulsion polymerization: An investigation into the compatiblization. Eur. Polym.J. 43, 336 (2007).

[11] K. G. Gopchandran, B. Joseph, J. T. Abraham, P. Koshy, V. K. Vidyan, The preparation of transparent electrically conducting indium oxide films by reactive vacuum evaporation, Vacuum, 48, 547(1997).

[12] J. Benny, K.G. Gopchandran, P. V. Thomas, P. Koshy, V. K. Vaidyan, Optical and electrical properties of zinc oxide films prepared by spray pyrolysis. Mater Chem Phys. 58, 71(1999).

[13] S. G. Lee, S. Lee, H. I. Lee, Photocatalytic production of hydrogen from aqueous solution containing $\mathrm{CN}$ as a hole scavenger, Appl Catal A, 207, 173(2001).

[14] M. J. Escudero, X. R. Novoa, T. Rodrigo, L. Daza, Study of a Li-Ni oxide mixture as a novel cathode for molten carbonate fuel cells by electrochemical impedance spectroscopy, J Appl Electrochem, 32, 929 (2002).

[15] M. Ando, J. Zehetner, T. Kobayashi, M. Haruta, Large optical CO sensitivity of $\mathrm{NO}_{2}$-pretreated $\mathrm{Au} / \mathrm{NiO}$ composite films, Sens Actuators B, 36, 513 (1996).

[16] M. Hosseini, The effect of cation composition on the electrical properties and aging of Mn-CoNi thermistors, Ceram. Int., 26, 245 (2000)

[17] Esmaiel Soleimani and Mostafa Mohammadi, Synthesis, characterization and properties of polystyrene/NiO nanocomposites, journal of Materials Science:Materials in Electronics , 29, 9494 (2018).

[18] A. Costoyas, J. Ramos, J. Forcada, Encapsulation of silica nanoparticles by miniemulsion polymerization, J. Polym. Sci. A, 47, 935 (2009).

[19] S. W. Zhang, S. Zhou, Y. M. Weng, L. M. Wu, Synthesis of $\mathrm{SiO}_{2} /$ polystyrene nanocomposite particles via miniemulsion polymerization. Langmuir, 21, 2124 (2005).

[20] F.Yan, J. Li, J. Zhang, F. Liu, W. Yang, Preparation of $\mathrm{Fe}_{3} \mathrm{O}_{4} /$ polystyrene composite particles from monolayer oleic acid modified $\mathrm{Fe}_{3} \mathrm{O}_{4}$ nanoparticles via miniemulsion polymerization. $\mathrm{J}$. Nanopart. Res. 11, 289 (2009).

[21] P.S. Nair, T. Radhakrishnan, N. Revaprasadu, C.G.C.E. van Sittert, V. Djokovic, A. S. Luyt, Characterization of polystyrene filled with $\mathrm{HgS}$ nanoparticles. Mater. Lett. 58, 361 (2004).

[22] J. Chen, G. Cheng, Y. Chai, W. Han, W. Zong, J. Chen, C. Li, W. Wang, L. Ou, Y. Yu, Preparation of nano- $\mathrm{CaCO}_{3} /$ polystyrene nanocomposite beads for efficient bilirubin removal. Colloids Surf. B 161, 480 (2018).

[23] H. Qiao, Z. Wei, H. Yang, L. Zhu, X. Yan, Preparation and Characterization of NiO Nanoparticles by Anodic Arc Plasma Method, Journal of Nanomaterials, 2009, Article ID 795928. 
[24] A. Haider, M. Ijaz, S. Ali, J. Haider, M. Imran, H. Majeed, I. Shahzadi, M. M. Ali, J. A. Khan, M. Ikram, Green Synthesized Phytochemically (Zingiber officinale and Allium sativum) Reduced Nickel Oxide Nanoparticles Confirmed Bactericidal and Catalytic Potential, Nanoscale Research Letters, 15, 1 (2020).

[25] A. L. Patterson, The Scherrer Formula for I-Ray Particle Size Determination, Physical Review, 56, 978 (1939).

[26] J. Aseeri, N. M. Alandis, W. Mekhamer, M. Alam, Miscibility studies of polystyrene/polyvinyl chloride blend in presence of organoclay, Open Chemistry, 17, 927 (2019).

[27] C. Borsoi, L. C. Scienza, A. J. Zattera, Characterization of Composites Based on Recycled Expanded Polystyrene Reinforced with Curaua Fibers, Journal of Applied Science, 128, 653 (2013).

[28] F. JunFei, X. YiMin, L. Qiang, Preparation of polystyrene spheres in different particle sizes and assembly of the PS colloidal crystals, Science China Technological Sciences, 53, 3088 (2010).

[29] M. M. Radhi, A. J. Haider, Z. N. Jameel, T. W. Tee, M. Z. B Ab Rahman, A. B. Kassim, Synthesis and Characterization of Grafted Acrylonitrile on Polystyrene modified with Carbon nanotubes using Gamma-irradiation, Research Journal of Chemical Sciences, 2, 1 (2012).

[30] B.T. Sone, X.G. Fuku, M.Maaza, Physical \& Electrochemical Properties of Green Synthesized Bunsenite $\mathrm{NiO}$ Nanoparticles via Callistemon Viminalis' Extracts, International Journal of Electrochemical Science, 11, 8204 (2016).

[31] T. Li, C. Zhou, M. Jiang, "UV absorption spectra of polystyrene," Polymer Bulletin, 25, 211(1991).

[32] Y. Zhao, F. Wang, Q. Fu, W. Shi. Synthesis and characterization of ZnS/hyper branched polyester nanocomposite and its optical properties. Polymer (Guildf) ;48, 2853 (2007).

[33] P. Maji, R. Bilash Choudhary, M. Majhi, Structural, electrical and optical properties of silanemodified $\mathrm{ZnO}$ reinforced PMMA matrix and its catalytic activities, J. Non-Cryst. Solids 456, 40(2017)

[34] Gh.O. Abdullah. and S. A Saleem., Effect of Copper Sulfide Nanoparticles on the Optical and Electrical Behavior of Poly(vinyl alcohol) Films, J. Electron Mater, 45 , 5910 (2016).

[35] F. Urbach., The Long-wavelength Edge of Photographic Sensitivity and of the electronic Absorption of Solids, Phys. Rev., 92, 1324 (1953).

[36] N.F. Mott. and N.F. Davis., Electronic process in non-crystalline materials. $2^{\text {nd }}$ ed. USA. Oxford university press(1979).

[37] V. Dimitrov, S. Sakka. Linear and nonlinear optical properties of simple oxides. II. J Appl Phy, 79,1741 (1996).

[38] Ahmed Y.Yassin, Abdel- Raouf Mohamed, Elmetwaly M. Abdelrazek, Muhamed A. Morsi and Amr M. Abdelghany, Structural investigation and enhancement of optical, electrical and thermal properties of poly(vinyl chloride-co-vinyl acetate-co-2-hydroxypropyl acrylate)/graphene oxide nanocomposites. J Mater Res Technol., 8, 1111 (2019). 
[39] J. F. Scott, Phase transitions in BaMnF4, Rep. Prog. Phys., 42, 1055 (1979).

[40] A. K. Jonscher, Dielectric relaxation in solids. Publisher; Chelsea Dielectric Press, London, 1983.

[41] A. R. Long, Frequency-dependent loss in amorphous semiconductors, Adv. Phys. 31, 553 (1982).

[42] S. R. Elliot, A.c. conduction in amorphous chalcogenide and pnictide semiconductors, Adv. Phys. 36, 135 (1987).

[43] K. Funke, Jump relaxation in solid electrolytes, Prog. Solid State Chem. 22, 111 (1993).

[44] C. Cramer, K. Funke, B. Roling, T. Saatkamp, D. Wilmer, M. D. Ingram, A. Padel, M. Ribes and G. Taillades, Ionic and polaronic hopping in glass, Solid State Ionics 86-88, 481 (1996).

[45] S. J. Pas and R. D. Banhatti, K. Funke, Conductivity spectra and ion dynamics of a salt-inpolymer electrolyte, Solid State Ionics 177, 3135 (2006).

[46] S. R. Elliott, Frequency-dependent conductivity in ionically and electronically conducting amorphous solids, Sol. Stat. Ionics., 70/71, 27 (1994).

[47] M. Le. Stanguennec, S. R. Elliott, Frequency-dependent ionic conductivity in AgI$\mathrm{AgPO}_{3}$ glasses, Sol. Stat. Ionics., 73, 199 (1994). 
Figures

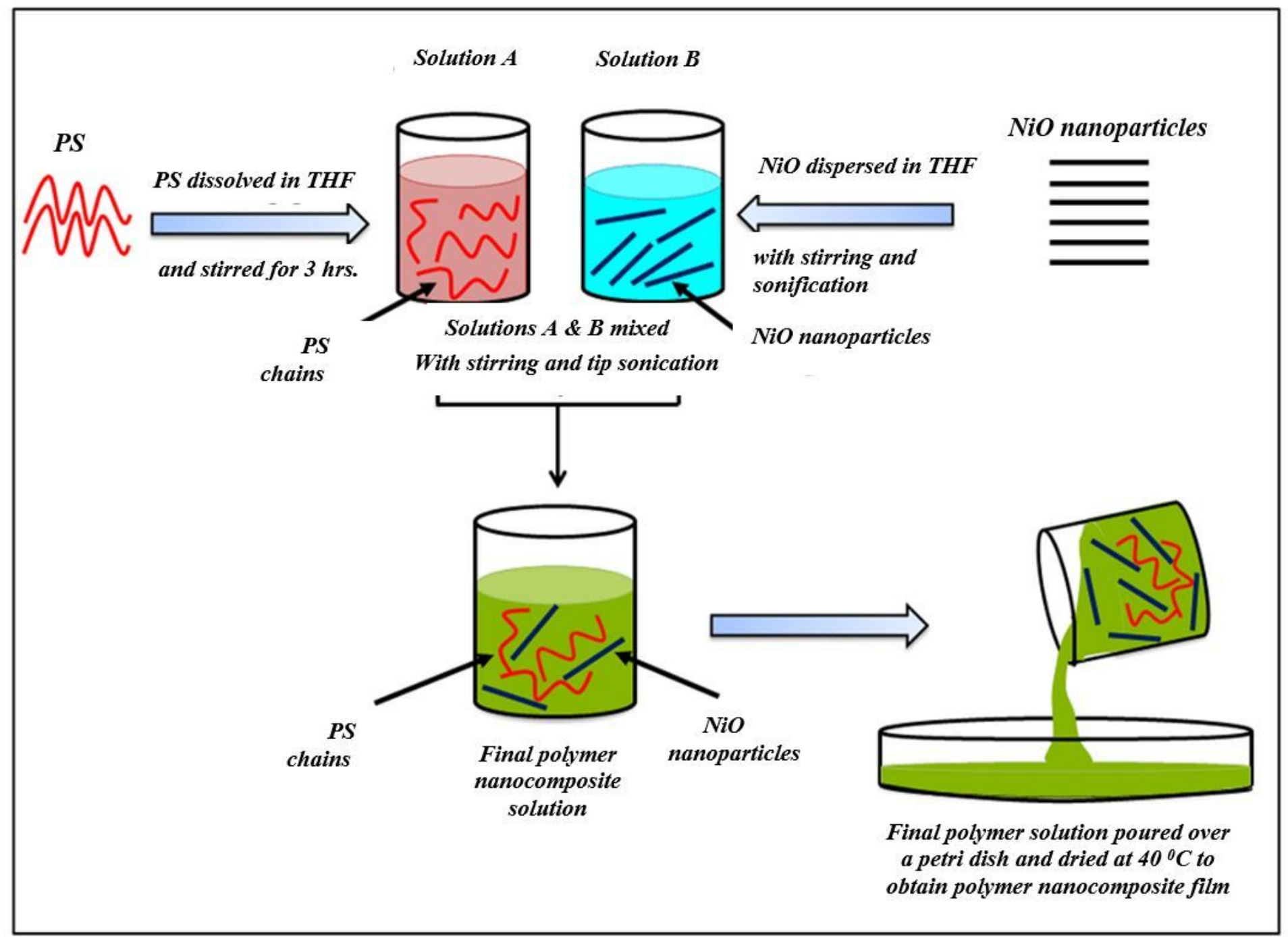

Figure 1

Fabrication steps involved in synthesis of PS/NiO nanocomposites using solution casting method. 


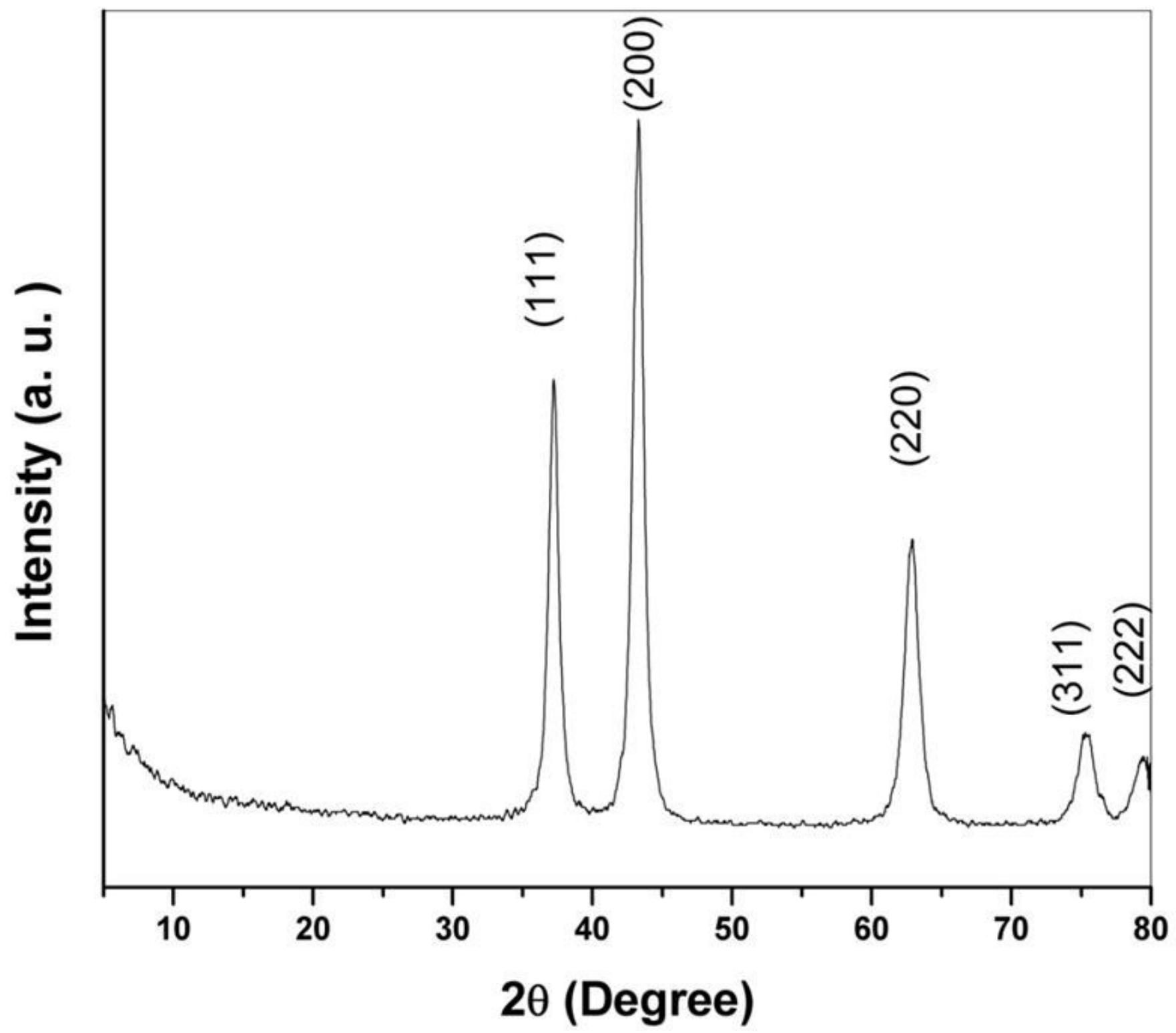

Figure 2

XRD pattern of NiO NPs 


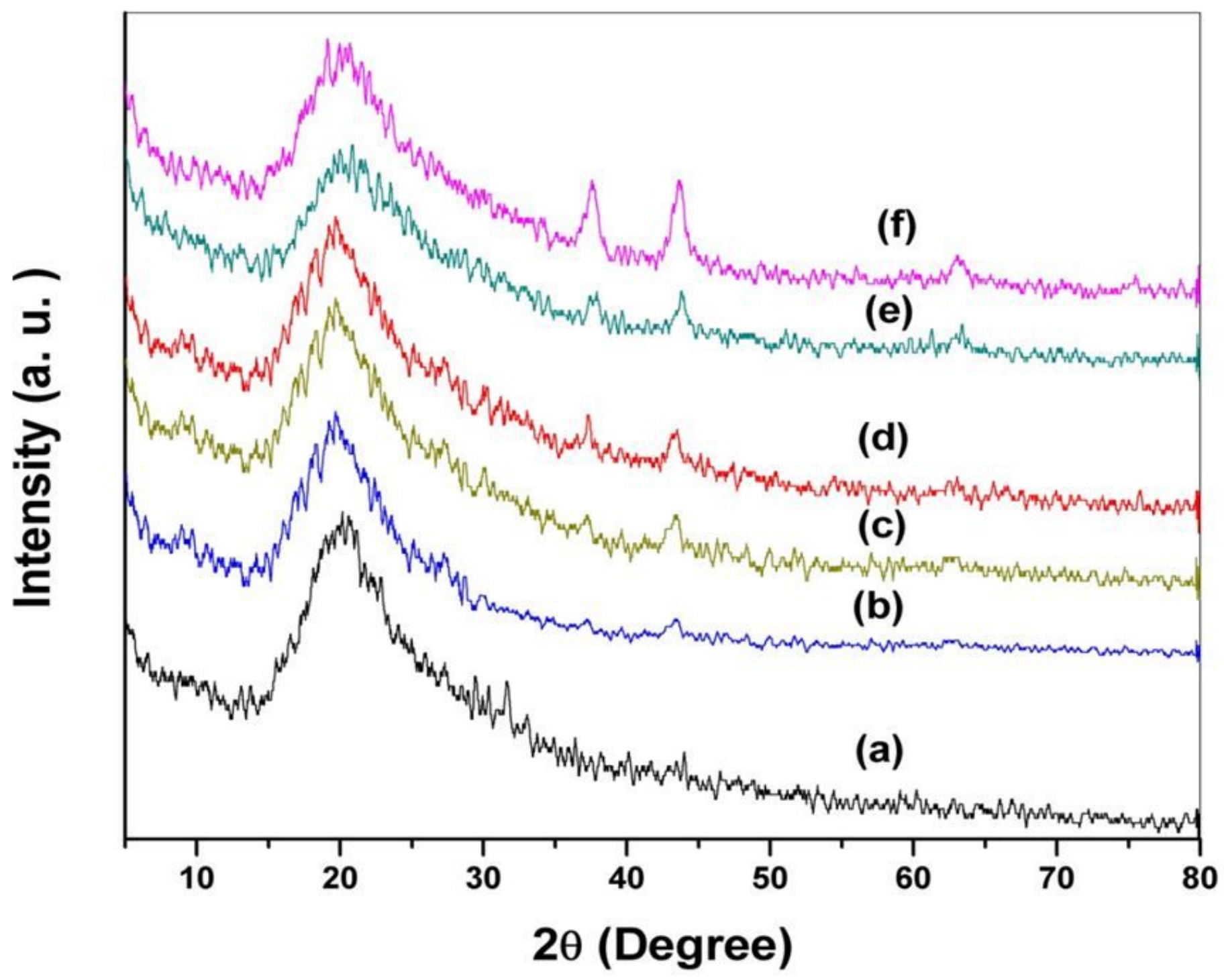

Figure 3

XRD patterns of PS sample doped with: (a) 0.0, (b) 2.0, (c) 4.0, (d) 6.0, (e) 8.0 and (f) 10.0 wt. \% of NiO nanoparticles. 


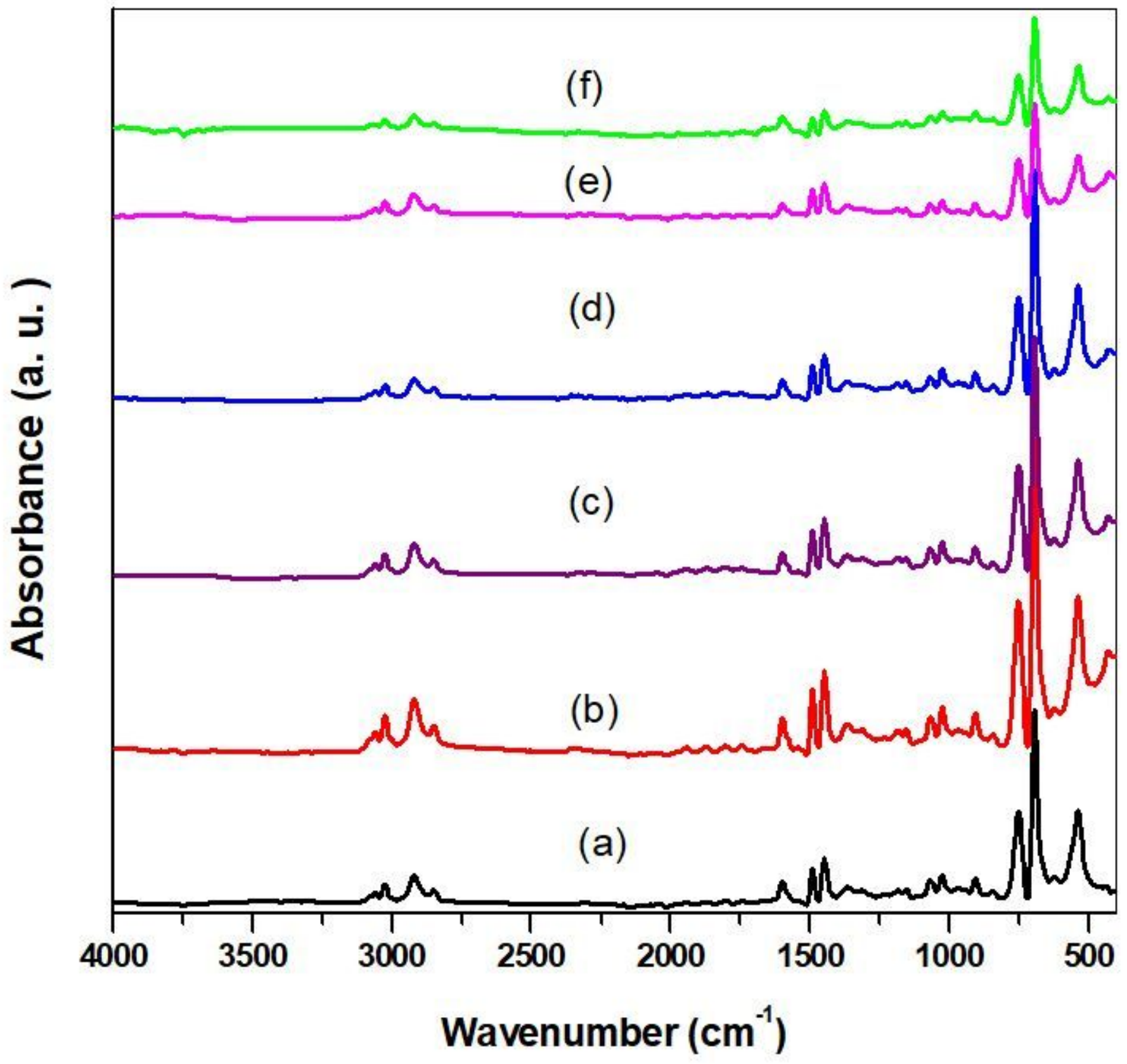

Figure 4

FT-IR spectra of PS sample doped with: (a) 0.0, (b) 2.0, (c) 4.0, (d) 6.0, (e) 8.0 and (f) 10.0 wt. \% of NiO nanoparticles. 

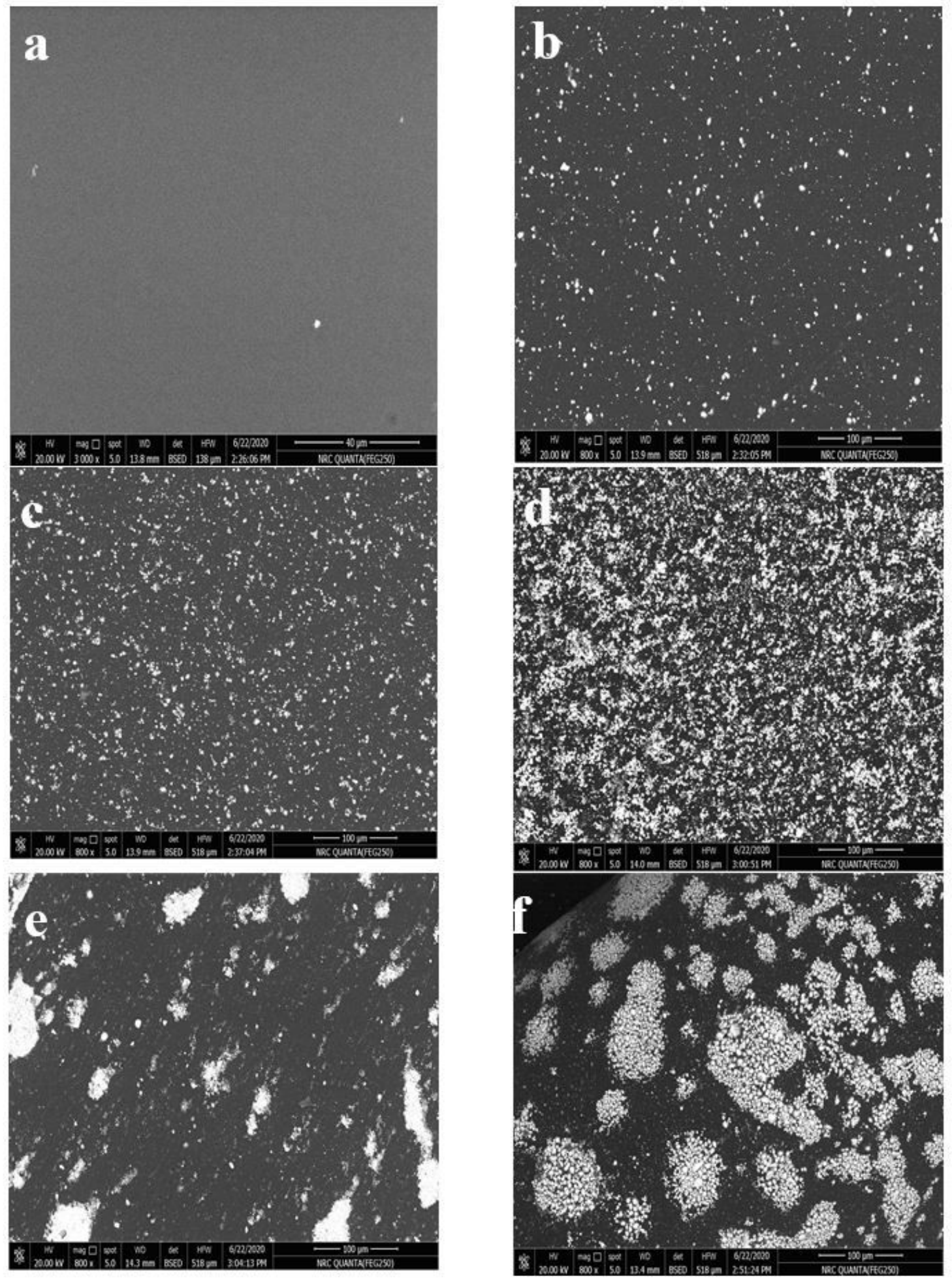

Figure 5

SEM images of PS sample doped with: (a) 0.0, (b) 2.0, (c) 4.0, (d) 6.0, (e) 8.0 and (f) $10.0 \mathrm{wt}$ \% of NiO nanoparticles. 


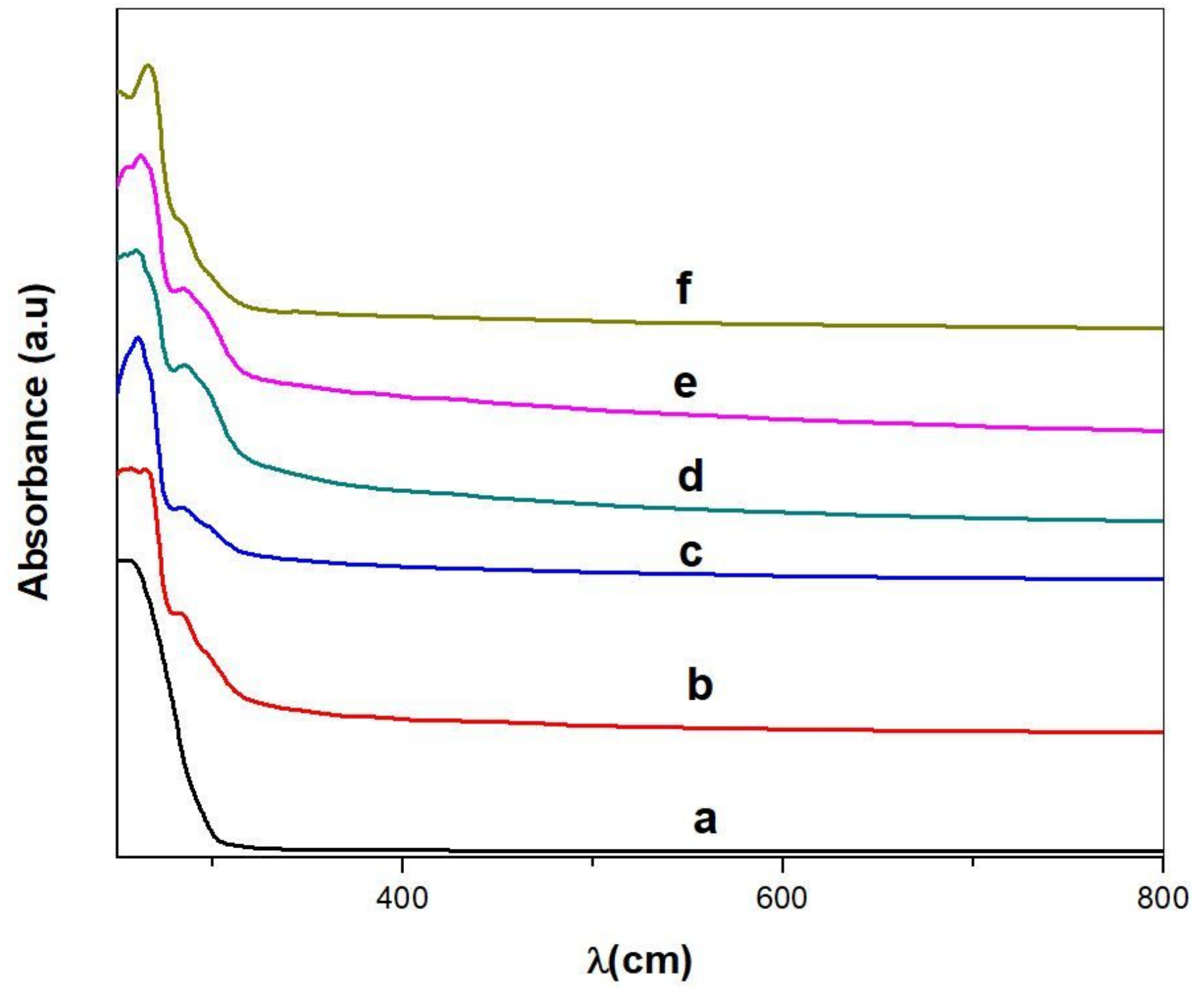

Figure 6

UV-Vis spectra of PS sample doped with: (a) 0.0, (b) 2.0, (c) 4.0, (d) 6.0, (e) 8.0 and (f) 10.0 wt. \% of NiO nanoparticles. 


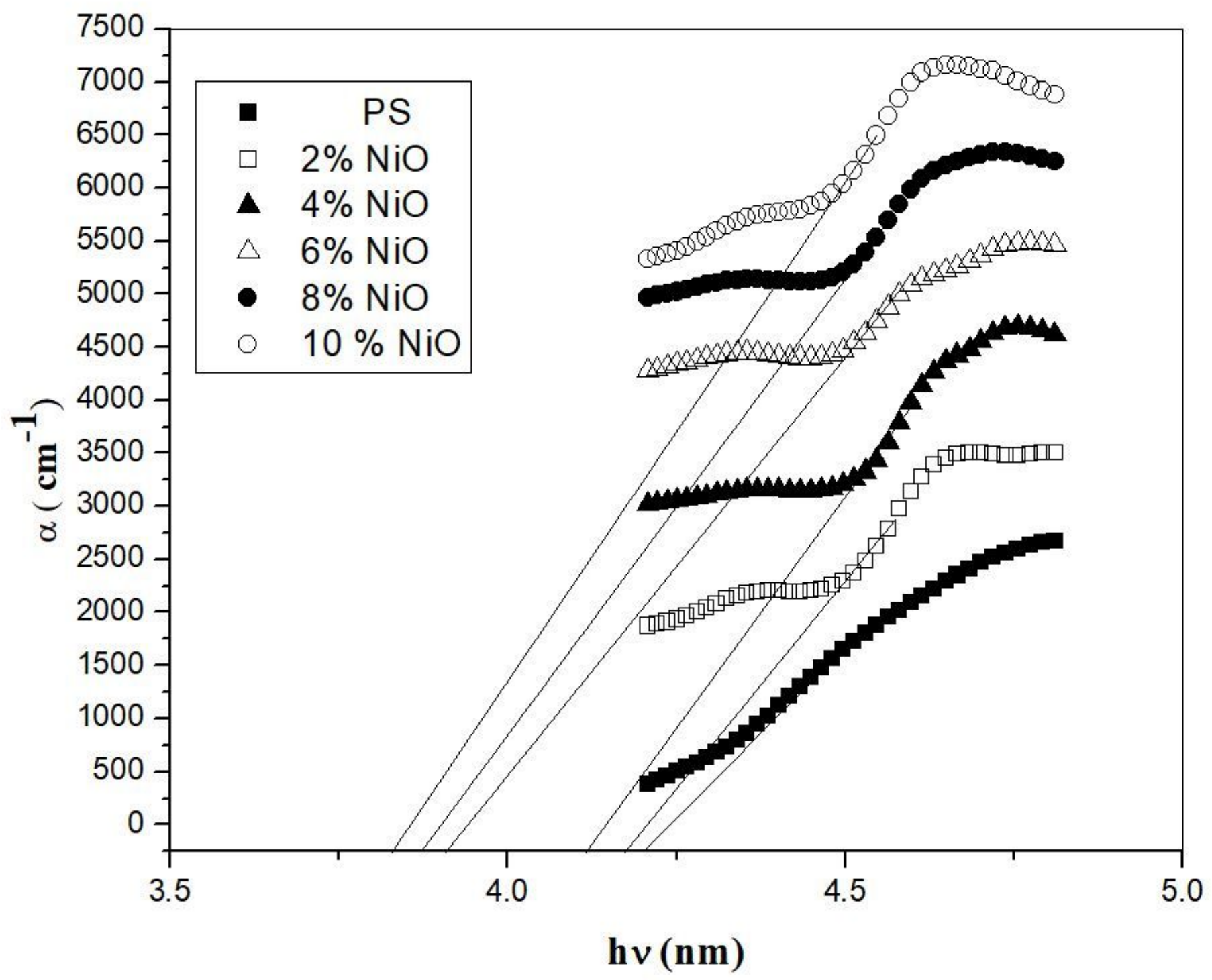

Figure 7

Absorbance coefficient (a) versus photon energy (hu) for Pure PS and PS/NiO NCs. 


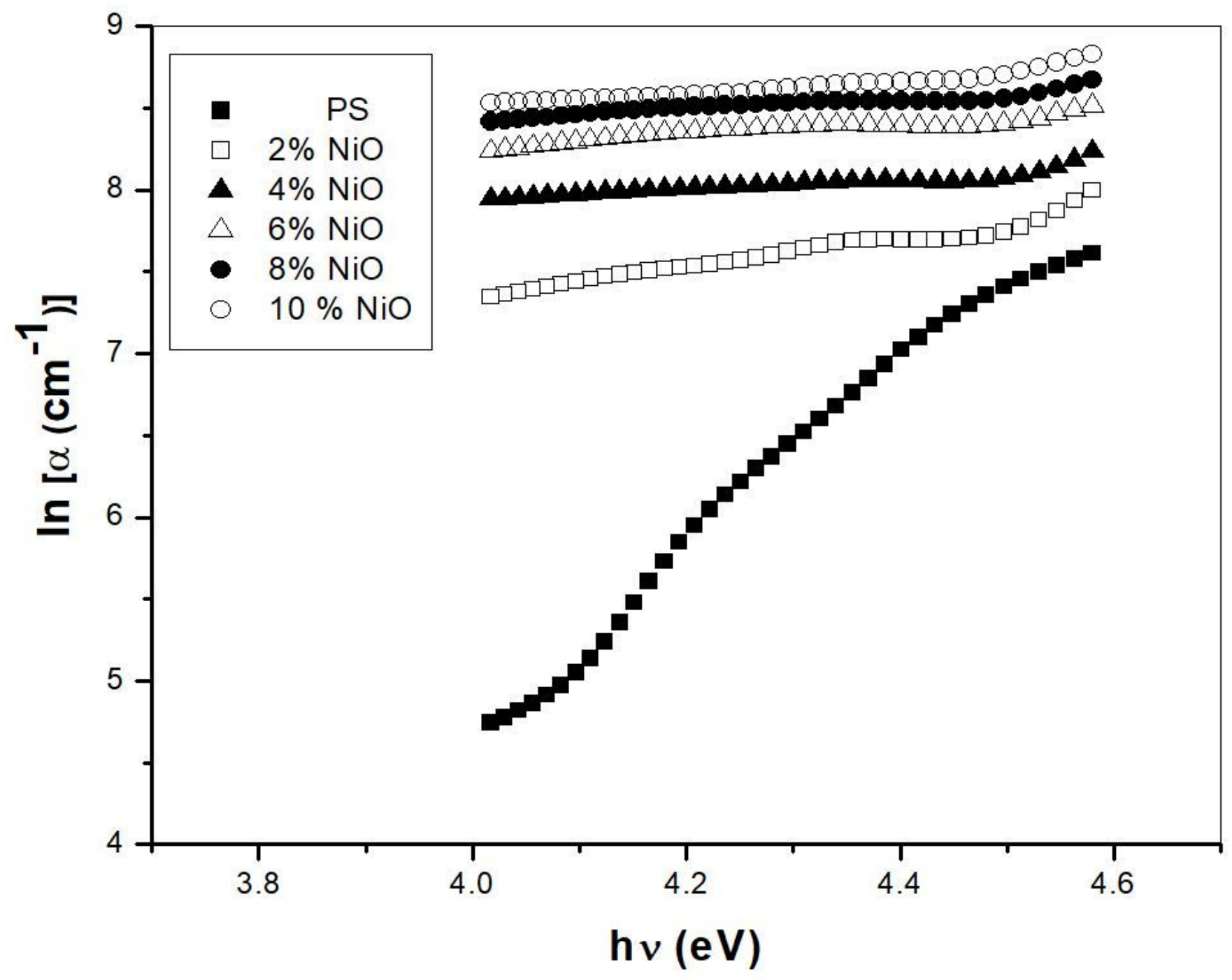

Figure 8

Relation between In (a) versus photon energy (hu) for Pure PS and PS/NiO NCs. 

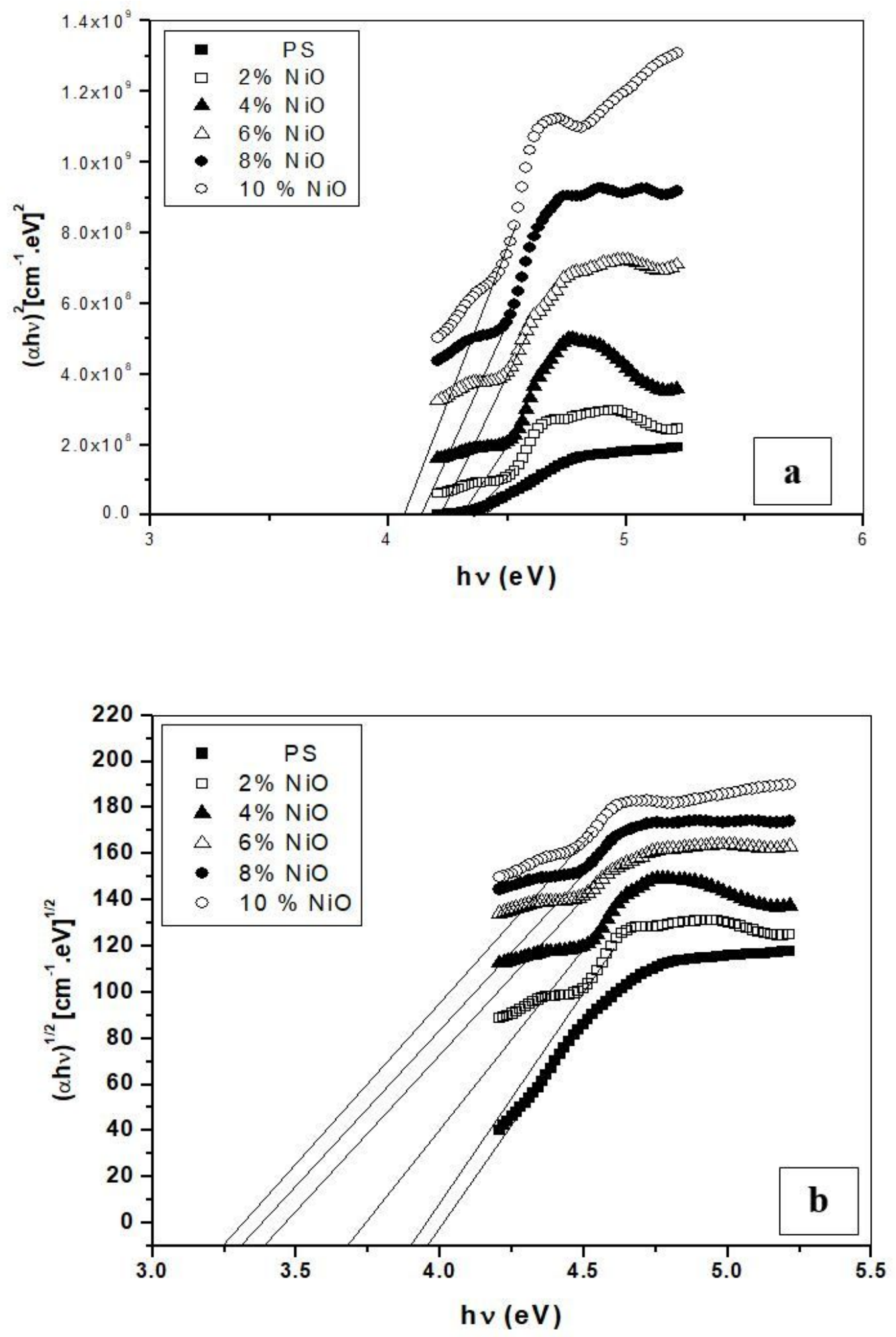

Figure 9

Relation between (ahu)2 and (ahu)1/2 versus photon energy (hu) for Pure PS and PS/NiO NCs. 


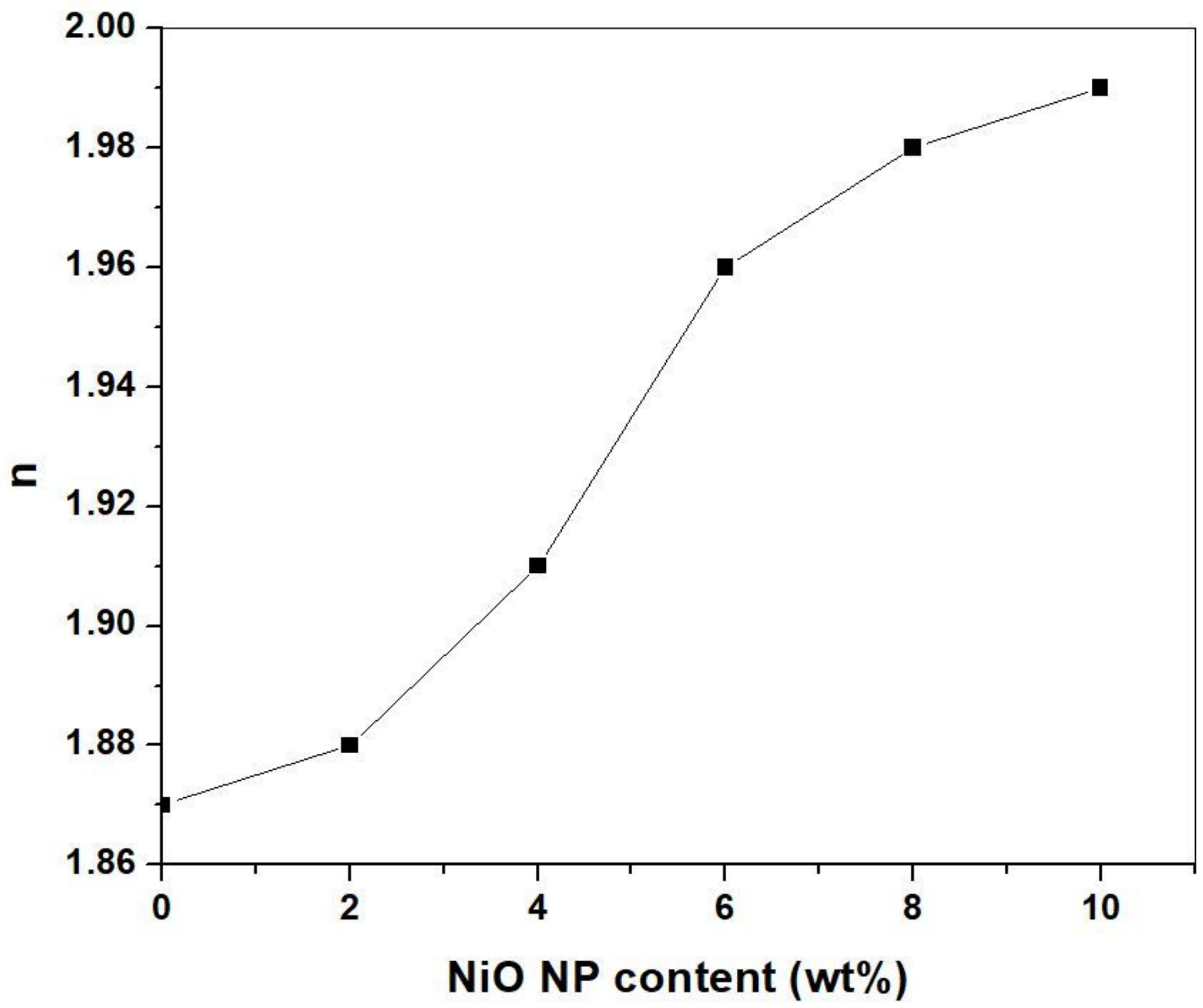

Figure 10

The calculated refractive indices of PS/NiO NCs with different NiO content. 


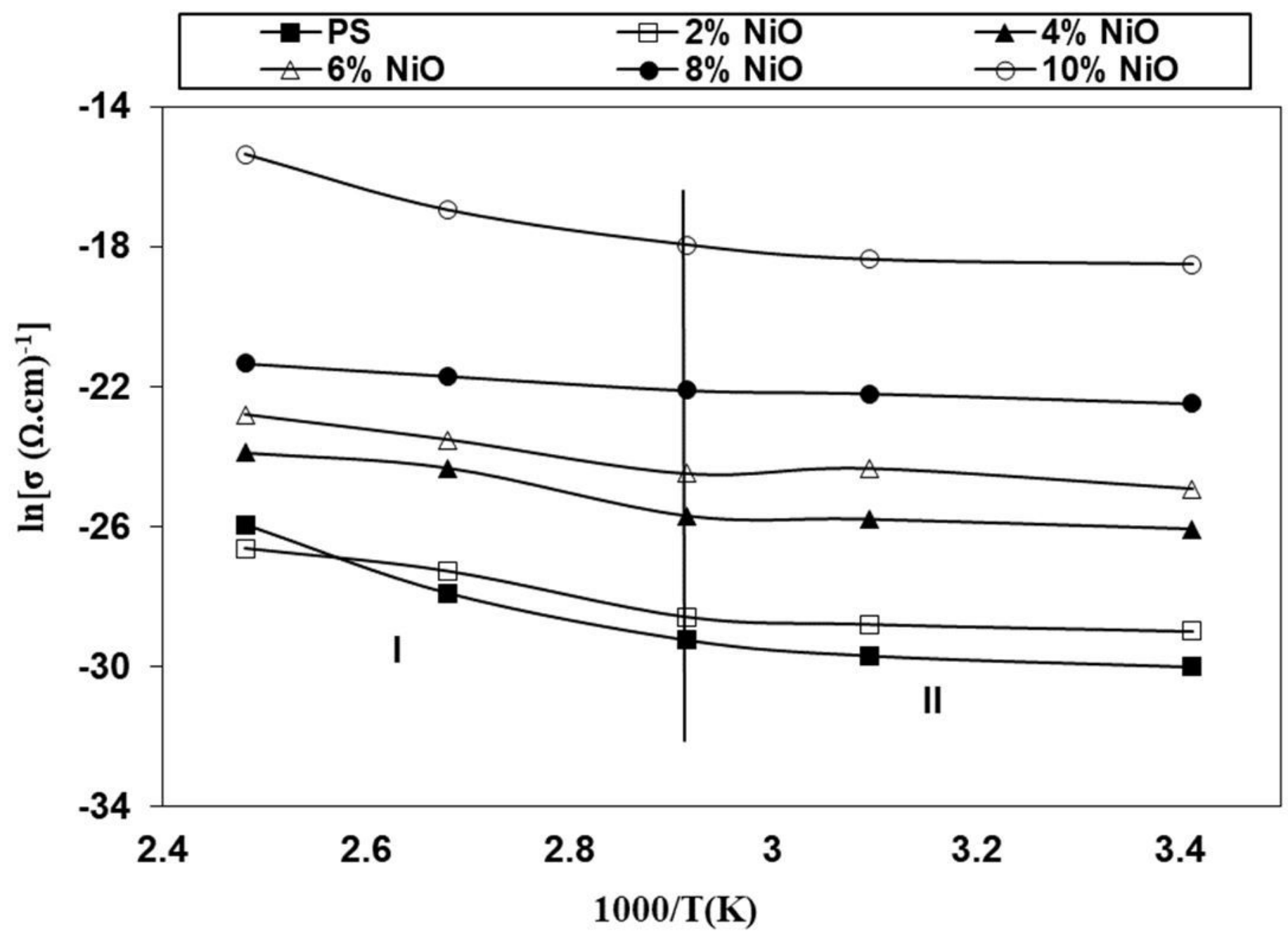

Figure 11

Arrhenius plot of conductivity and 1000/T for PS/NiO nanocomposites at $1 \mathrm{kHz}$. 

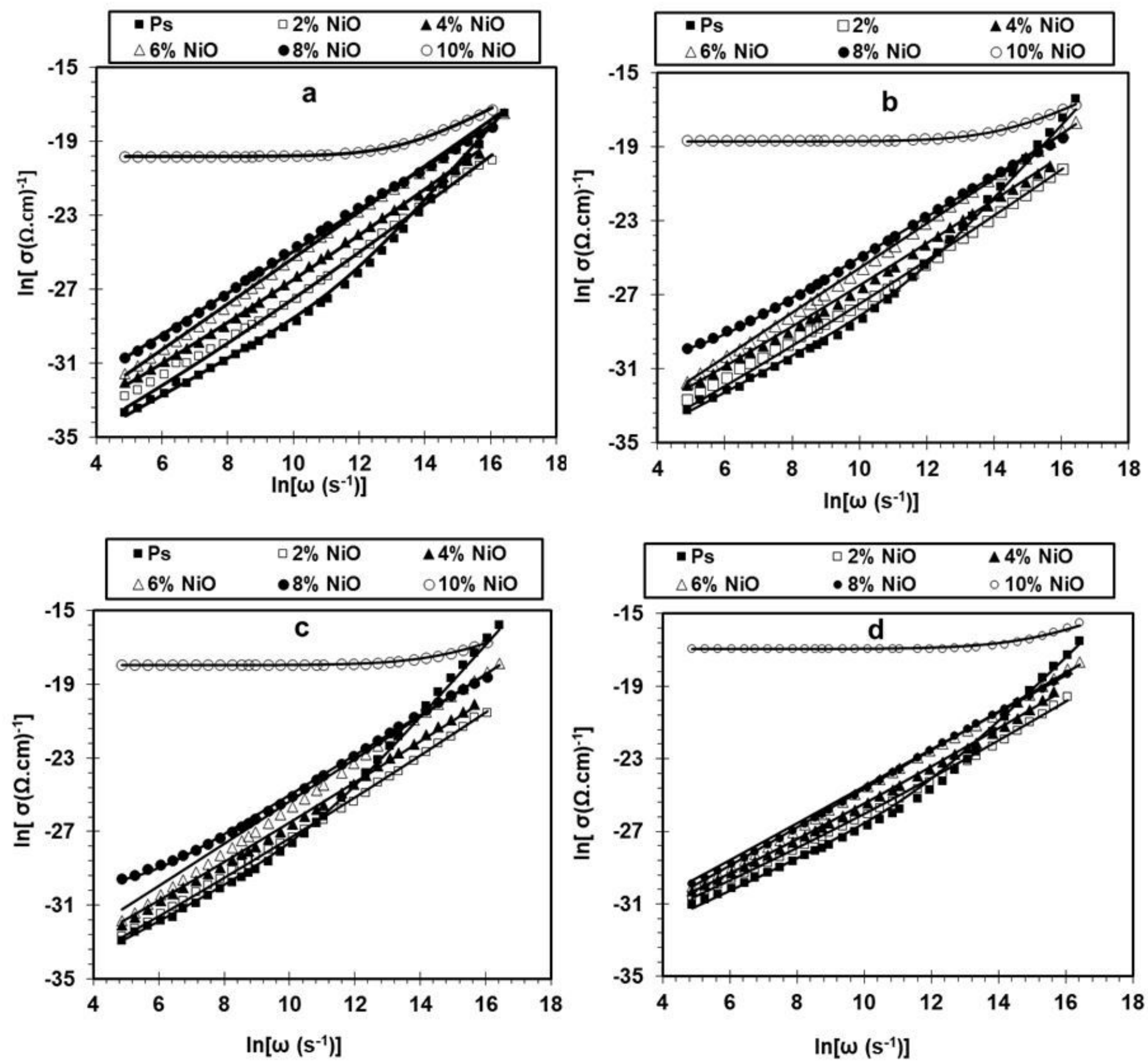

Figure 12

Relation between Ac conductivity [In $\sigma(\omega)]$ and $[\ln (\omega)$ for PS/NiO nanocomposite samples at different temperatures: (a) $20 \mathrm{oC}$, (b) $50 \mathrm{oC}$, (c) $70 \mathrm{oC}$, (d) $100 \mathrm{oC}$. The solid lines display the fitting data according to Eq.(8) except $10 \% \mathrm{NiO}$ sample fitted to Eq.(7). 


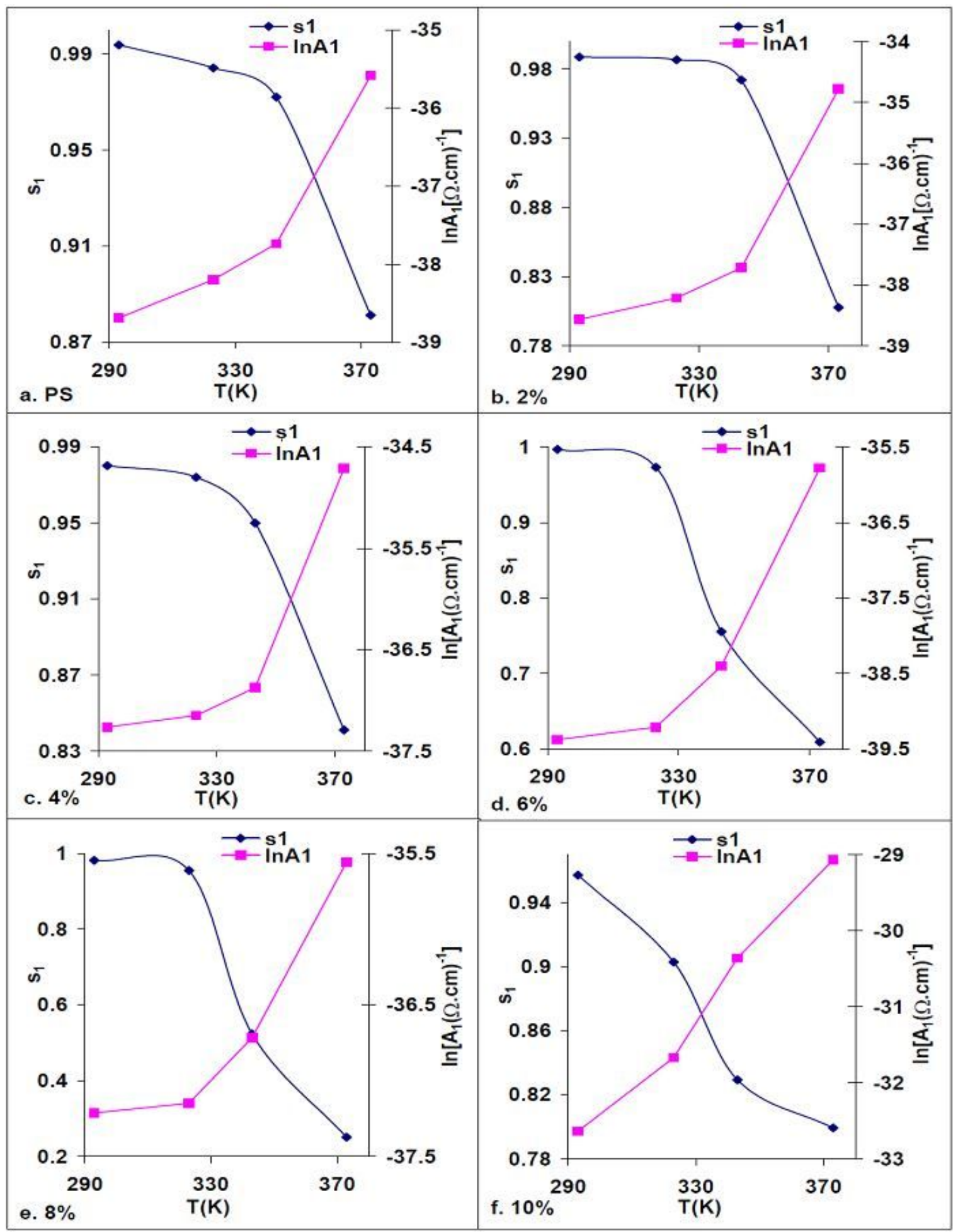

Figure 13

Thermal variation of the factor $\mathrm{A} 1$ and the exponent s1 for (a) PS, (b) $2 \% \mathrm{NiO}$, (c) $4 \% \mathrm{NiO}$, (d) $6 \% \mathrm{NiO}$, (e) $8 \% \mathrm{NiO}$ fitted to Eq.(8) and (f) $10 \% \mathrm{NiO}$ fitted to Eq.(7). 


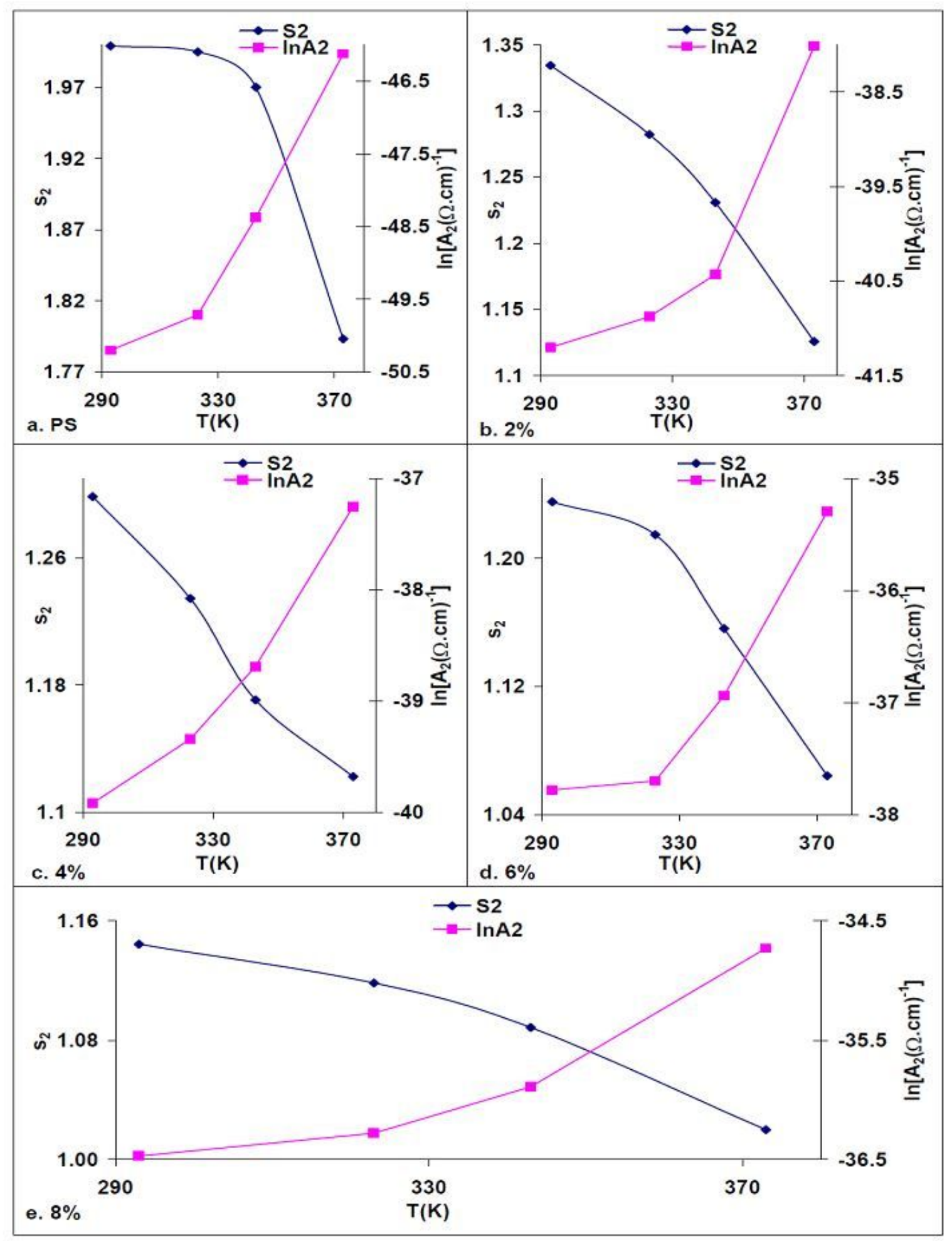

Figure 14

Thermal variation of the factor $\mathrm{A} 2$ and the exponent s2 for (a) PS, (b) $2 \% \mathrm{NiO}$, (c) $4 \% \mathrm{NiO}$, (d) $6 \% \mathrm{NiO}$, and (e) $8 \% \mathrm{NiO}$ fitted to Eq. (8).

\section{Supplementary Files}


This is a list of supplementary files associated with this preprint. Click to download.

- declarationofcompetinginterests.doc

- highlight.doc 